Volume 9, No.1, January - February 2020

International Journal of Advanced Trends in Computer Science and Engineering

Available Online at http://www.warse.org/IJATCSE/static/pdf/file/ijatcse47912020.pdf

https://doi.org/10.30534/ijatcse/2020/47912020

\title{
Design of Warehouse Management System for Fresh Product in Supply Chain Network
}

\author{
Ali Khumaidi ${ }^{1}$, Heru Sukoco ${ }^{2}$, Y. Aris Purwanto ${ }^{3}$, Avip Kurniawan ${ }^{4}$ \\ ${ }^{1,4}$ Department of Informatics, Engineering Faculty, University of Krisnadwipayana, Indonesia, \\ alikhumaidi@unkris.ac.id \\ ${ }^{2}$ Department of Computer Science, Bogor Agricultural University, Indonesia, hsrkom@ipb.ac.id \\ ${ }^{3}$ Department of Mechanical and Biosystem Engineering, Bogor Agricultural University, Indonesia, \\ arispurwanto@apps.ipb.ac.id
}

\begin{abstract}
Warehouse management has an important role in maintaining product quality. Moreover, warehouses that handle fresh products are perishable and have a limited shelf life. therefore it is necessary to design smart warehouse management so that products can be accepted by customers with optimal quality. The supply chain network $(\mathrm{SCN})$ is a model used to reduce costs and time efficiency. Previous research generally discusses the use of RFID, WSN and genetic algorithms for monitoring and decision making of products in supply chains and warehouses but does not focus on fresh products and warehouse management with the SCN model. The design a smart warehouse management system (SWMS), by integrating WSN, RFID and hybrid genetic algorithms (GA) with a combination of Analytical Hierarchy Process (AHP) for increased accuracy and optimization. For tracking and monitoring fresh products using Radio Frequency Identification (RFID) technology, temperature sensors, humidity sensors, and ultrasonic sensors. The SWMS design consists of 4 sub-systems: Smart Logistic, Adaptive Warehouse Inventory, Smart Forecasting System, and Smart Decision Support System.
\end{abstract}

Key words : RFID, WSN, Warehouse, Fresh Product

\section{INTRODUCTION}

Warehouse management has an important role in maintaining product quality. Moreover, warehouses that handle fresh produce, which is sensitive to temperature and shelf life require more complex systems to be more efficient and accurate and need to be built an environmental monitoring system for humidity, temperature, air, and light [1]. Shelf life is a safe time for perishable products so that it still fulfills physical, chemical and microbiological characteristics [2]. Temperature is one of the parameters to control the freshness and quality of products, especially perishable products [3]. For perishable products to have an optimal shelf life, proper handling is needed starting from packing, storage, and distribution [4]. The warehouse of fresh products accommodates various types of fruits and vegetables with different temperature and humidity requirements so that the storage is adjusted to its characteristics [5]. To provide fresh products with optimal quality to customers is needed the supply chain network ( $\mathrm{SCN}$ ) is a model to reduce costs and time efficiency [6][7][8]. SCN manages the flow of information from production to consumption to adjust customer needs [9]. SCN model activities are shown in figure 1.

There are several problems in the management of warehouse fresh products, first is the process of ordering products that are adjusted to the trend and the number of requests and delivery to the warehouse following capacity of the pallet space for fresh product characteristics. Second is the placement of fresh products in locations with suitable temperatures. Strategies to maintain product quality and safety by monitoring temperature conditions during storage in warehouses, through mapping of appropriate locations [10]. Errors in the placement and taking of fresh products due to inaccurate inventory [11]. Humans can cause errors in the process of placing and sending [12]. Third is the prediction of requests from customers so that it can reduce product damage due to too long storage, and wrong estimation of delivery time [13]. The fourth is the product data collection so that issue is the product with the least shelf life. Temperature monitoring, shelf life visibility, and least shelf life first out stock strategy are important in the logistics of perishable products and to reduce economic and quality losses [14]. The fifth is communication between policyholders between warehouses, this is due to the involvement of many warehouses in SCN.

RFID is one of automatic identification and data capture technologies [15]. RFID utilizes radio waves to transmit, identify, track, sort, and confirm various objects [16][17]. compared to barcodes, RFID has waterproof properties, has a magnetic scratch-resistant protective layer, is heat-resistant, durable, able to transmit long-distance and short data transmission, data encryption, and has a greater memory capacity [18]. RFID consists of two components, tag, and 
reader. Based on the RFID category is divided into two, namely RFID with an active RFID power supply/tag and without a passive power / RFID tag [19]. Wireless sensor networks (WSN) have been widely used in research because of their good flexibility and lower costs compared to cable installations [20][21][22]. WSN is a system consisting of transceivers, sensors, microcontrollers, and power sources. WSN has the characteristics of self-organizing, self-configuring, self-diagnosing, and self-healing. These properties are an advantage of WSN that did not exist in previous technologies [23][24][25]. RFID and WSN have been widely applied in research. WSN can provide environmental information, with integration with RFID can be applied to a wider function and lower costs compared to the existing warehouse management system [26]. Literature studies related to RFID and WSN for monitoring and tracking the quality of agricultural products have been carried out to reduce food product degradation strategies [27][28]. Genetic Algorithm (GA) is a method for optimization based on the concept of biological evolution from Darwin's theory [29]. GA uses random search techniques with natural selection mechanisms and natural genetics. GA can find the optimal solution in a complex multidimensional search that has many parameters. GA was successfully applied in various fields to solve many optimization problems [30][31][32].

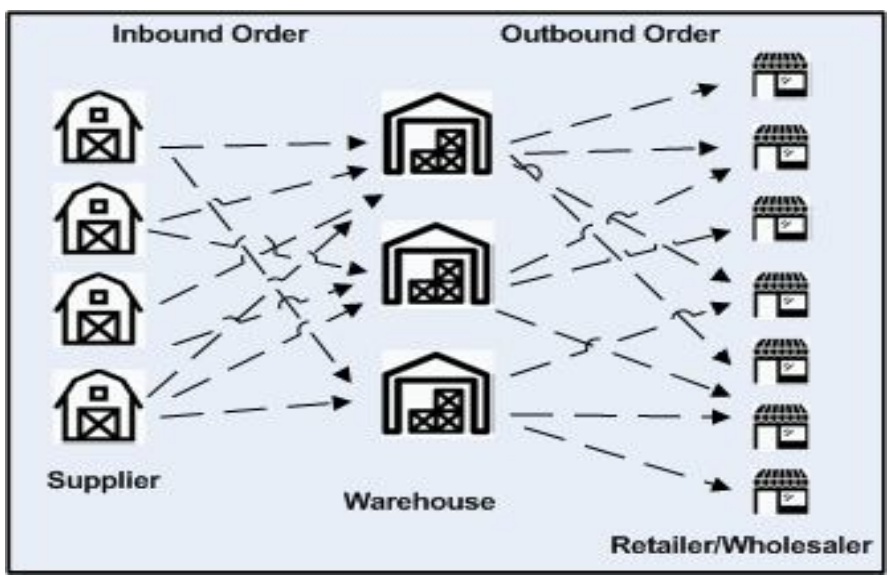

Figure 1: The three level supply chain network

Research related to warehousing and supply chain has so far discussed the use of RFID and WSN for perishable products even though it does not focus on fresh products [33][34][35] [36][37]. Research on decision support systems with genetic algorithms in warehouse management addresses layout and location allocation problems [38][39], order picking problems [40], optimization of item placement [41], production and distribution problems with multi factories for the same quality products [42]. But there has been no research that addresses the optimization of warehouse management with RFID and WSN using Algortima Genetics in SCN.
In this paper, we designed a smart warehouse management system (SWMS) by implementing WSN, RFID, and genetic algorithms to solve problems. By proposing architecture and SWMS design consists of 4 sub-systems: Smart Logistics, Adaptive Warehouse Inventory, Smart Forecasting System, and Smart Decision Support System. The relationship of the sub-system is shown in figure 2.

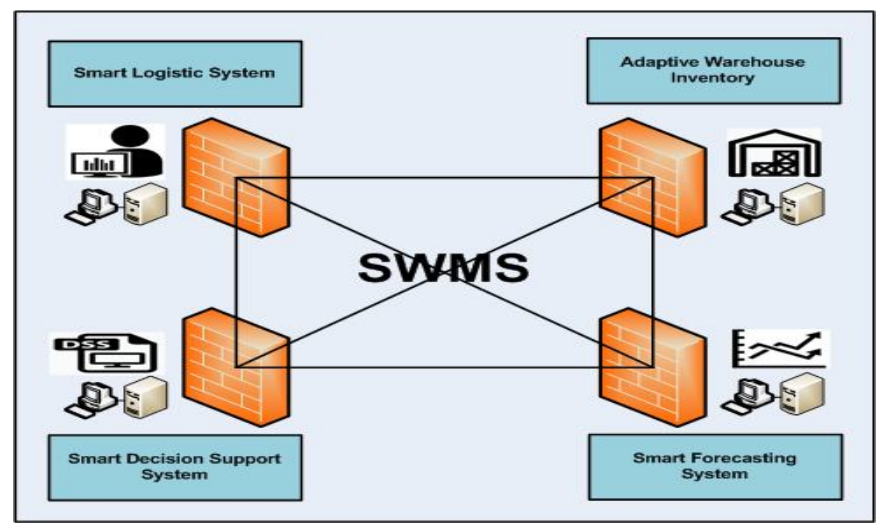

Figure 2: Smart Warehouse Management System Proposed

\section{RESEARCH METHOD}

This research contributed to the development of Smart Warehouse Management System (SWMS) with a combination of RFID, WSN, GA and AH technology. The contributions include designing network architecture and work systems and application integration models in the sub-systems, (1) Smart Logistic with a combination of genetic algorithms and AHP for optimizing product shipping to customers and orders to suppliers, (2) Adaptive Warehouse Inventory for data collection and product management fresh in the warehouse, (3) Smart Forecasting System to predict customer requests and orders to suppliers, (4) Smart Decision Support System to support decisions and communication between managerial level in each warehouse.

\section{THE ARCHITECTURE OF PROPOSED SYSTEM}

The proposed architectural system for warehouse management of fresh products, as shown in Figure 3. It is assumed there are many warehouse locations with the following work systems. First, the fresh product comes from the supplier, then the product is sorted and packed and then put in a box. Products and boxes will be affixed with RFID tags. The box will be placed on the pallet according to the RFID tag data. Determination of the location of pallets and decision making products on the box using the Smart Logistics system based on GA and AHP processing. Products that have a shelf life of zero or have expired are prioritized for sales to juice beverage manufacturers. The warehouse has a location mapping based on the characteristics and types of 
products with different temperature and humidity values. In each pallet installed temperature sensors, humidity sensors and ultrasonic sensors to detect storage capacity.

Sensors collect temperature, humidity and altitude data and then aggregate and acquire data. The gateway forwards to the local server system for processing before sending it to the cloud. Due to the large amount of sensor data and can use up bandwidth, an analysis is performed first to reduce the burden on the data center. Merging data from several warehouses will be processed deeper into the data center by using data mining so that it can produce an accurate and optimal decision system.

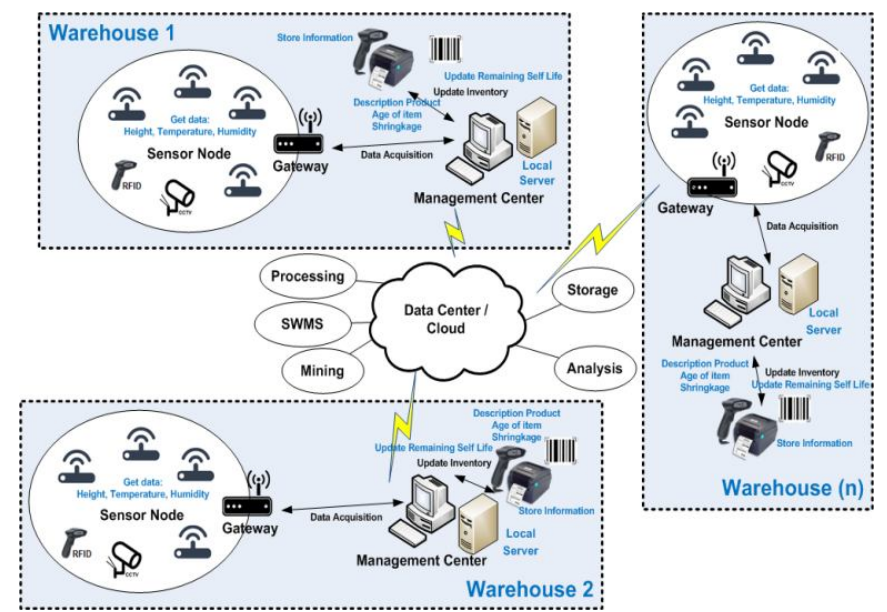

Figure 3: The SWMS Topology and Architecture

\section{SWMS DESIGN}

Developing a SWMS using the 3-tier concept, as in Figure 4. First is the presentation layer, which is the interface for users to enter the system. The second is the business logic layer, which is responsible for processing various logical calls. SWMS logic and Management logic are the main parts of this layer. All decision making is the result of the calculation of the model built. Third is the data layer, which consists of four bases that can communicate with each other through logic management. In building SWMS using a 3-tier concept, as in Figure 4. First is the presentation layer, which is the interface for users to enter the system. The second is the business logic layer, which is responsible for processing various logical calls. SWMS logic and Management logic are the main parts of this layer. All decision making is the result of the calculation of the model built. Third is the data layer, which consists of four bases that can communicate with each other through logic management.

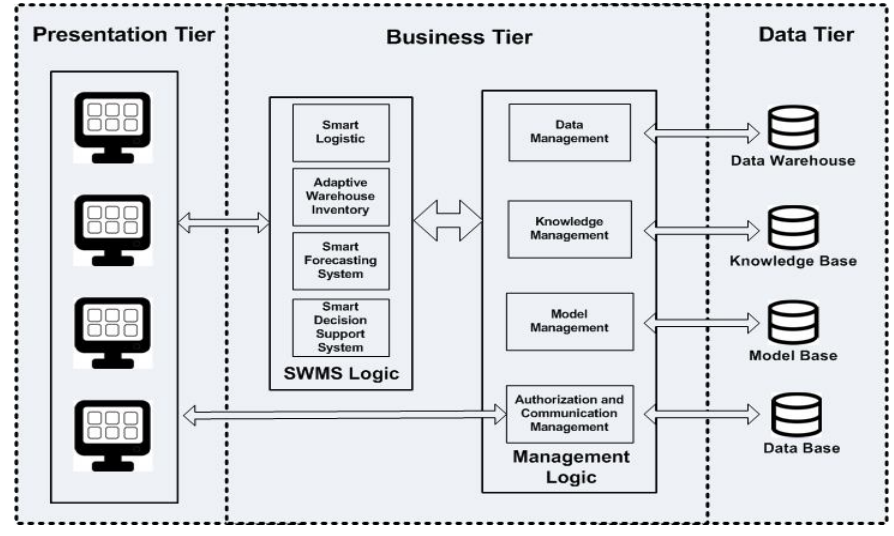

Figure 4: SWMS Application Architecture

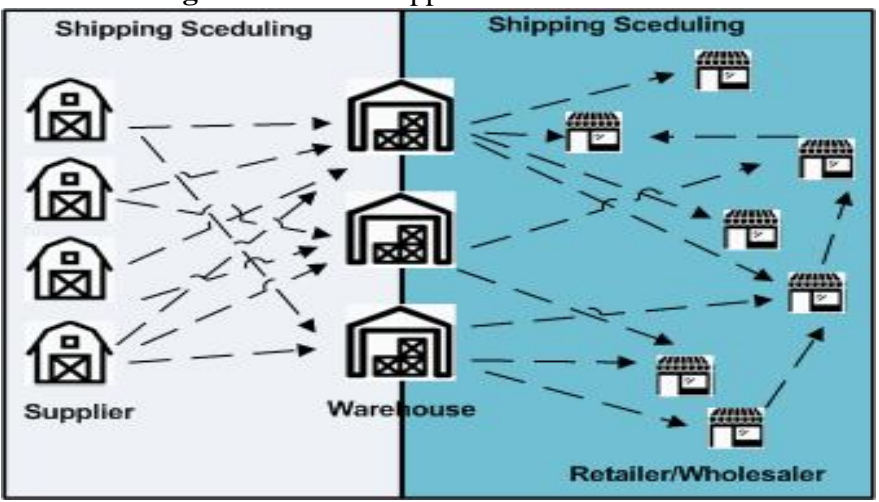

Figure 5: Smart Logistic Area

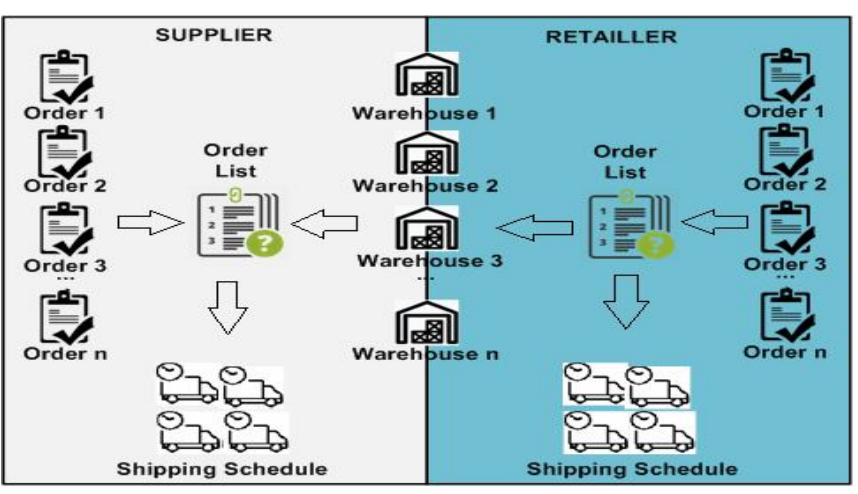

Figure 6: Smart Logistic Workflow

\subsection{Smart Logistic}

Smart Logistics is a subsystem for optimizing product expenditures to customers, making delivery scheduling and storing shipping data such as timeliness, product conditions and customer satisfaction. Figure 5 shows the scope of smart logistic work. To get optimal results using a combination of GA and AHP. Variables that are considered in determining the decision to release goods are customer location, warehouse location, product shelf life, customer type, shipping costs, number of orders, and delivery time. Figure 6 shows the Smart Logistic process flow, the process starts when there is an order from the customer, based on a specific time rule policy, all orders will be carried out by the system to determine the delivery schedule and transportation as well as the selected product code including box code, pallet code, and 
warehouse code. This system optimizes so that customers get fresh products with optimal quality and minimal costs, such as the problem description in Figure 7 . The notation and mathematical model of the problem can be formulated (1).

$$
\begin{array}{ll}
\mathrm{K} & =\{1,2,3, . . \mathrm{n} 1\}, \text { set of fresh produce, indexed by } \mathrm{k} \\
\mathrm{L} & =\{1,2,3, . . \mathrm{n} 2\}, \text { set of Warehouses, indexed by } \mathrm{l} \\
\mathrm{M} & =\{1,2,3, \ldots \mathrm{n} 3\}, \text { set of retailers, indexed by } \mathrm{m} \\
\mathrm{N} & =\{1,2,3, . . \mathrm{n} 4\}, \text { set of transportation, indexed by } \mathrm{n} \\
\mathrm{SL}_{\mathrm{m}}=\text { Shelf life of fresh produce } \mathrm{m} \in \mathrm{K} & \mathrm{SC}_{\mathrm{nm}}=\text { Shipping cost } \mathrm{m} \in \mathrm{L}, \mathrm{N} \\
\mathrm{LS}_{\mathrm{lm}} & =\text { Lead time shipping }
\end{array}
$$

$$
\operatorname{Min} \sum_{n=1}^{n 1} S L_{m}+\sum_{n=1}^{n \pi} \min _{i=1: n 2}\left\{S C_{m} * L S_{l m}\right\}
$$

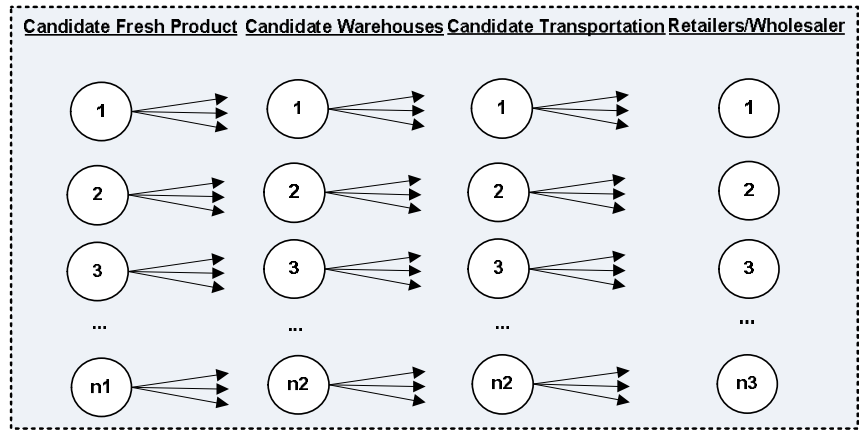

Figure 7: Problem Description

GA can only produce one solution but can be improved by a combination of other algorithms. Enhanced GA can obtain more than one solution, GA has three main operators, namely selection, crossover, and mutation. GA and AHP are applied to analyze logistical distribution location problems, GA to obtain some optimal solutions on economic factors and AHP to evaluate solutions [43]. This research proposes hybrid GA with an AHP combination. AHP is used to find the most important criteria which will then be processed by GA to obtain an optimal solution. The proposed hybrid GA-AHP algorithm is shown in figures 8 .

\footnotetext{
Pseudocode of hybrid GA-AHP

While (the solution does not optimal) do

Select the fittest $P(t)$ among $P(t)$ for next-generation;

Select two chromosomes from the population randomly, then

Crossover the two selected chromosomes which the point of crossover is randomly selected to get new chromosomes

Mutate the chromosomes in the population which the point of mutation is randomly selected to avoid premature convergence.

Rank the top five chromosomes with the AHP to get the new

population / children population $C(t)$

Evaluate the fitness of chromosome of $C(t)$ to get the optimal

current solution with the highest fitness among $C(t)$

Update the current condition

If previous solution < current solution, then replace the previous solution with current condition;

Select $P(t+1)$ from $P(t)$ and $C(t)$;

$T=t+1$;

End while;

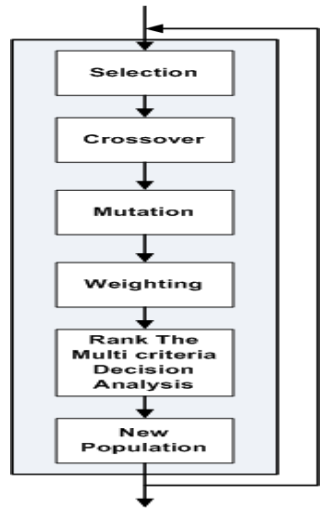

Figure 8: Propose Algorithm Hybrid GA-AHP 4.2. Adaptive Warehouse Inventory

Adaptive Warehouse Inventory (AWI) for data collection and managing fresh products in the warehouse to maintain product quality. AWI uses RFID technology, temperature sensors, humidity sensors, and ultrasonic sensors and microcontrollers. Fresh products have certain characteristics and the quality can be maintained optimally with certain temperatures and humidity. With temperature and humidity data can be used to control the engine coolant. Fuzzy Logic Control (FLC) is a technique to control using fuzzy operations. FLC on the microcontroller can be used to control the climate in the greenhouse [44][45]. Block Diagram FLC Model Proposed in figure 9. The ATmega32 microcontroller can be used at AWI as FLC communication, actuators and sensors as well as processing data for FLC. Data from the microcontroller will be used by FLC to obtain the desired environment by manipulating the actuator. AWI can manage RFID-based product, box and pallet data collection for all warehouses, components and block diagram setup proposed in Figures 10 and 11.

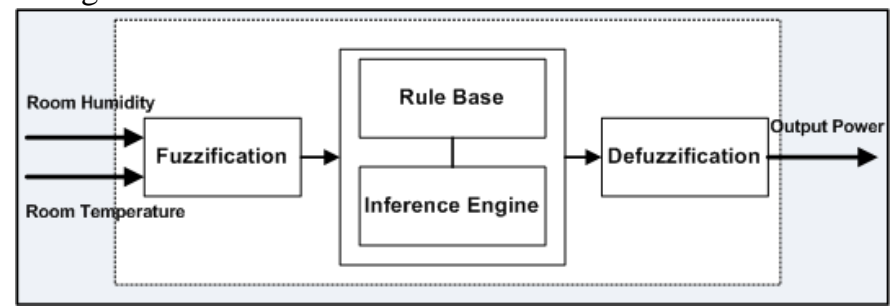

Figure 9: Block Diagram FLC Model Proposed

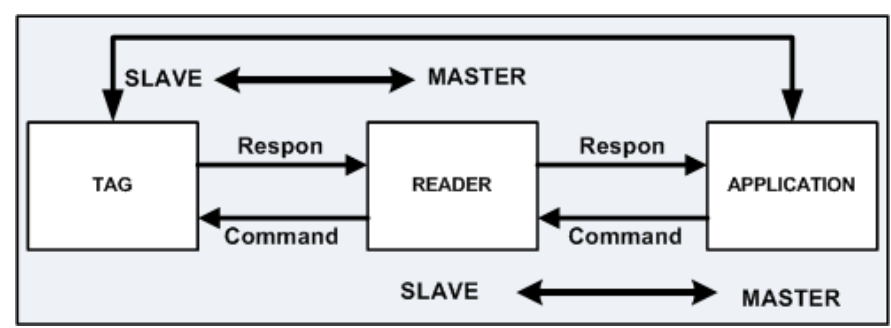

Figure 10: The Basic components of RFID 


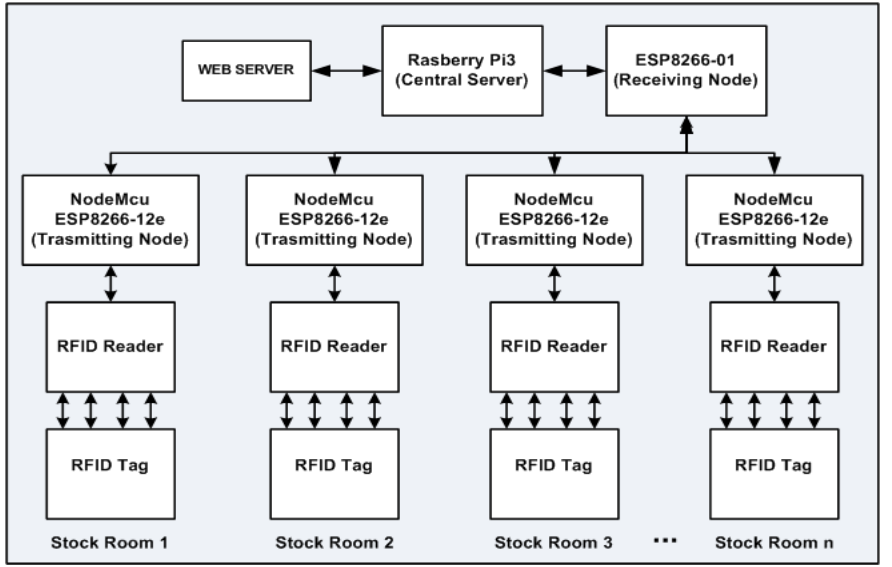

Figure 11: Block Diagram Setup Proposed

\subsection{Smart Forecasting System}

Smart Forecasting System (SFS) to predict customer demand and orders to suppliers so that they control stock and control. Using forecasting can reduce inventory costs, optimize stock, increase customer loyalty and increase profits. Fast Moving Consumer Goods (FMCG) is managing logistics and supply chains between producers and customers, how customers get services faster, lower costs and better [46]. FMCG with the presence of RFID technology makes improvements in efficiency, information accuracy, and speed. So that RFID is widely applied to logistics [47]. Figure 12 illustrates the scope of forecasting and the importance of management for predictions. Feedback data from Smart Logistic, RFID-based product data, availability of sensor-based storage data and inbound and outbound patterns in the warehouse are the basis for forecasting and planning.

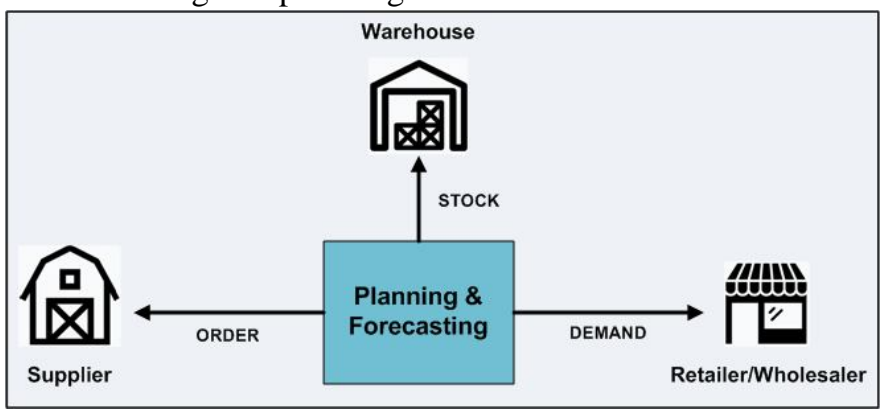

Figure 12: SFS Area

The forecasting method using an artificial intelligence approach results in better accuracy[47]. The SFS proposes using an artificial neural network (ANN) model with Least square support vector machine (LS-SVM) and Extreme Learning Machine (ELM) learning methods. This model consists of 3 layers, namely the input layer represents the factors that influence forecasting, the hidden layer which is the computational process and the output layer produces forecasting results, as in Figure 13.

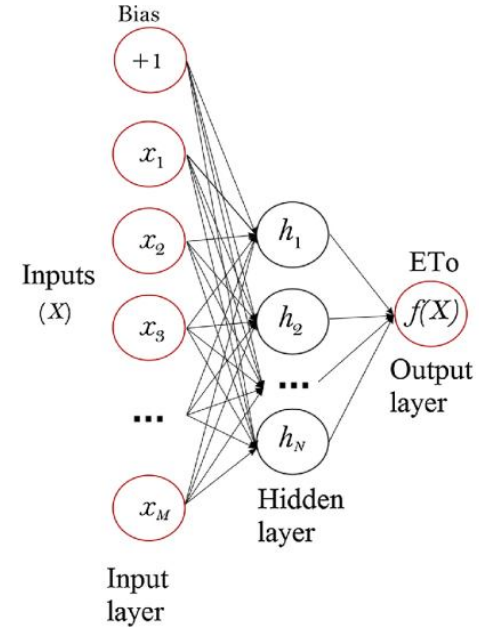

Figure 13: Structural architecture of ELM [48]

\subsection{Smart Decision Support System}

The consequence of applying the SCN model is communication with the warehouse manager in determining decisions that result in a long time. Therefore we need a Smart Decision Support System (SDSS) that can make it easy to unite ideas and views among members quickly and accurately. The managerial level in the presence of SDSS is helped to find the best alternative in evaluating SCN performance. Multi-Criteria Decision Making (MCDM) is a method of decision making to determine the best alternative from some alternatives based on certain criteria [49]. In developing SDSS, developing the MCDM framework with a combination of the best worst method (BWM), a new additive ratio assessment (ARAS) method and the Multiplicative Utility function. BWM has better consistency than AHP [50] and has a more efficient weight calculation [51]. ARAS method is used to solve multi-criteria problems [52]. ARAS method and Multiplicative Utility function is used for evaluation and ranking. SDSS can be used for decision making in evaluating suppliers, products, transportation, and retailers/wholesalers.

\section{CONCLUSION}

We have designed network architecture and work systems as well as SWMS integration models with 4 sub-systems: Smart Logistics, AWI, SFS, and SDSS. By combining RFID technology, WSN, GA algorithm, AHP algorithm, Fuzzy algorithm, LS-SVM, and ELM artificial neural network models, BWM forecasting models, ARAS function models and Multiplicative Utility Functions. The choice of technology and algorithm with a combination of the results of previous studies are expected to achieve the best optimization. The next research will implement and test the combination of technology and algorithm proposed. 


\section{REFERENCES}

1. Wang, J. et al., "Software Design of Warehouse Supervision System Based on RFID and SN" Microcomputer Information, 2009, 2, 227-229

2. Sousa Gallagher, M.J., Mahajan, P.V., Yan, Z., "Modelling chemical and physical deterioration of foods and beverage. Elsevier , 2011, pp. 459-481 https://doi.org/10.1533/9780857092540.2.459

3. Zhang, J., Liu, L., Mu, W., Moga, L. M. \& Zhang, X. "Development of temperature managed traceability system for frozen and chilled food during storage", Journal of Food Agriculture and Environment, 2009, 7, 28-31

4. Richard A. Holley, Dhaval Patel, "Improvement in shelf life and safety of perishable foods," Food Microbiology. 2005, 22, Issue 4, 273-292

5. Do Nascimento Nunes, Maria Cecilia, "Impact of environmental conditions on fruit and vegetable quality", Stewart Postharvest. 2008, 4, 1-14

https://doi.org/10.2212/spr.2008.4.4

6. Cardenas Barron L.E., Porter J.D., "Supply chain models for an assembly system with preprocessing of raw materials", Applied Mathematical Modelling. 2013, 37, 7883-7887

7. T. Sawik, "Coordinated supply chain scheduling", Int. Journal of Production Economics. 2009. 120 (2), 437-451.

https://doi.org/10.1016/j.ijpe.2008.08.059

8. Bashiri M., Badri H., Talebi J., "A New Approach to Tactical and Strategic Planning in Production Distribution Networks", Applied Mathematical Model. 2012, 36 (4), 1703-1717.

9. Cordeau J.F., Pasin F., Solomon M.M., "An Integrated Model for Logistics Network", Annal. Operation. Res. 2006, 144 (1), 59-82

10. Giulia Baruffaldi, Riccardo Accorsi, Daniele Santi, Riccardo Manzini, Francesco Pilati, "Chapter 9 - The storage of perishable products: A decision-support tool to manage temperature-sensitive products warehouses", Editor(s): Riccardo Accorsi, Riccardo Manzini, Sustainable Food Supply Chains, Academic Press, 2019, 131-143

11. Rekik Y, Sahin E, Dallery Y., "Analysis of the impact of the RFID technology on reducing product misplacement errors at retail stores", Int. Journal of Production Economics. 2008, 112, 264-278 https://doi.org/10.1016/j.ijpe.2006.08.024

12. Ilaria Giusti, Elvezia Maria Cepolina, Edoardo Cangialosi, Donato Aquaro, Gabriella Caroti, Andrea Piemonte,"Mitigation of human error consequences in general cargo handler logistics: Impact of RFID implementation," Computers \& Industrial Engineering. 2019, 137

13. Yahaya SM and Mardiyya AY, "Review of Post-Harvest Losses of Fruits and Vegetables", Biomedical Journal of Scientific \& Technical Research, 2019, 13, 10192-10200
14. Lin Qi, Mark Xu, Zetian Fu, Trebar Mira, Xiaoshuan Zhang, "C2SLDS: A WSN based perishable food shelf life prediction and LSFO strategy decision support system in cold chain logistics", J. Food Control. 2014, 38(1), 19-29 https://doi.org/10.1016/j.foodcont.2013.09.023

15. Potdar, V., Wu, C., \& Chang, E, "Automated data capture technologies: RFID. In J. Symonds (Ed.), Ubiquitous and pervasive computing: Concepts, methodologies, tools, and applications", 2010, 82-111. Hershey, PA: IGI-Global.

16. Roberts, C. M. (2006). "Radio frequency identification (RFID). Computers \& Security", 2005, 25(1), 18-26.

17. Liu, C. M., \& Chen, L.S., "Applications of RFID technology for improving production efficiency in an integrated-circuit packaging house", Int. Journal of Production Research, 2009, 47(8), 2203-2216 https://doi.org/10.1080/00207540802380556

18. Bi C., Cao J., Sheng X., "Radio frequency identification technology and its application in the library", Int. Conference on Information Computing and Applications. Berlin: Springer. 2011, 646-651

19. Ramanathan R., Ramanathan U., Wan L., Ko L., "Adoption of RFID technologies in UK logistics", Int. J. Expert Systems With Applications, 2014, 41(1), 230-236

20. Saeed N.A., "Efficient Technique for Reducing Transmission Energy of Sensor Node to Enhance the Lifetime of the WSN", Int. Journal of Advanced Trends in Computer Science and Engineering, 2019, 8(2), $108-111$ https://doi.org/10.30534/ijatcse/2019/02822019

21. Chen J., Li P., Song G., Ren Z., "Piezo-based wireless sensor network for early age concrete strength monitoring," Int. Journal for Light and Electron Optics, 2016, 127(5), 2983-2987

22. Chen J., "Model based compensation for overcoming sensor breakdown in a piezo based wireless sensor network," Int. Journal for Light and Electron Optics, 2016, 127(5), 3138-3142 https://doi.org/10.1016/j.ijleo.2015.11.177

23. Wang N., Zhang N., Wang M., "Wireless sensors in agriculture and food industry recent development and future perspective," Journal Computers and Electronics in Agriculture, 2006, 5(1), 1-14

24. Ravindra S.K., Agrawal S., Manoj S., Bhaskar U.B., Jasmine M.P.P.,"Automated Toll Booth using Optical Character Recognition and RFID System", Int. Journal of Advanced Trends in Computer Science and Engineering, 2019, 8(4), 1056-1061 https://doi.org/10.30534/ijatcse/2019/11842019

25. Tampa, Fla, Baggio A., "Wireless sensor networks in precision agriculture," Proceedings of the ACM Workshop on Real World Wireless Sensor Networks, Stockholm, Sweden, June 2005

26. Liu G., "Design and implementation of logistics warehouse management system based on RFID and 
WSN," ICLEM Logistic Sustainable Economic Devevelopment. 2010, 387, 2503-2509.

27. Fabien Bibi, Carole Guillaume, Nathalie Gontard, Brice Sorli, "A review: RFID technology having sensing aptitudes for food industry and their contribution to tracking and monitoring of food products," Journal Trends in Food Science and Technology, 2017, 62, 91-103

28. Bouzembrak Y, Kluche M., Gavai A., Marvin H.J.P., "Internet of Things in food safety: Literature review and a bibliometric analysis", Journal Trends in Food Science and Technology, 2019, 94, 54-64

29. Goldberg D., "Genetic Algorithms in Search, Optimization and Machine Learning", Addison-Wiley Publishing Company, Massachusetts, Mass, USA, 1989

30. Seval Ene, İlker Küçükoğlu, Aslı Aksoy, Nursel Öztürk, "A genetic algorithm for minimizing energy consumption in warehouses," Energy, 2016, 114, 973-980

31. Tzafestas S.G., Poulos P., Rigatos G.G., Koukos A., “A Genetic Algorithm for Warehouse Multi-Objective Optimisation," IFAC Proceedings, 2000, 33, Issue 17, 963-969 https://doi.org/10.1016/S1474-6670(17)39534-4

32. Beroule B., Grunder O., Barakat O., Aujoulat O., "Order Picking Problem in a Warehouse Hospital Pharmacy", IFAC - Papers OnLine, 2017, 50, Issue 1, pp. 5017-5022

33. Ricardo B.M., Javier G.H., Luis R.G., Tatiana J.A.0, Ignacio J.R.V., Barreiro P., "Assessing the dynamic behavior of WSN motes and RFID semi-passive tags for temperature monitoring", Journal Computers and Electronics in Agriculture, 2014, 103, 11-16

34. Bibi F., Guillaume C., Gontard N., Sorli B., "A review: RFID technology having sensing aptitudes for food industry and their contribution to tracking and monitoring of food products", Journal Trends in Food Science and Technology, 2017, 62, 91-103

35. Jedermann R., Garcia L.R., Lang W., "Spatial temperature profiling by semi-passive RFID loggers for perishable food transportation," Journal Computers and Electronics in Agriculture, 2009, 65, Issue 2, 145-154 https://doi.org/10.1016/j.compag.2008.08.006

36. Min M.A, Seok Y.C., "Temperature management for the quality assurance of a perishable food supply chain," Journal Food Control, 2014, 40, 198-207

37. Shin Y.K., Jin H., Ryou O., Han Y.L., "A simulation approach for optimal design of RFID sensor tag based cold chain systems," Journal of Food Engineering, 2012, 113, Issue 1, 1-10

38. Matic D., Filipovic V., Savic A., "A Genetic Algorithm For Solving Multiple Warehouse Layout Problem," Kragujevac Journal of Mathematics. 2011, 35(1), 119-138

39. Dalila B.M.M. F, Paulo A. P., Fernando A.C.C.F., "A Decision Support System for TV self-promotion Scheduling", International Journal of Advanced Trends in Computer Science and Engineering, 2019, 8(2), $134-140$ https://doi.org/10.30534/ijatcse/2019/06822019

40. Kiris, Safak, Deliktaş, Derya, Ustun, Ozden, Stanimirovic Z., "Order Picking Problem in a Warehouse with Bi-objective Genetic Algorithm Approach: Case Study," The 15th International Logistics and Supply Chain Congress, At Turkey, Istanbul. October 2017

41. Qin G., Li J., Jiang N., Li Q., Wang L., "Warehouse Optimization Model Based on Genetic Algorithm," Mathematical Problems in Engineering, 2013

42. Chan F., Chung S., Wadhwa S., "A hybrid genetic algorithm for production and distribution," Omega, 2005, 33(4), 345-355

43. Li, Ji, Dong, Huailin, "Research on Logistics Distribution Center Location Problem Based on Genetic Algorithm and AHP", 4th international Conference on Computer Science and Education, 2009

44. Javadikia P., Tabatabaeefar A., Omid M. M., Alimardani R., Fathi M., "Evaluation of Intelligent Greenhouse Climate Control System", International Conference on Artificial Intelligence and Computational Intelligence. 2009, 145-150

45. Ranggadara I., "Fuzzy Tsukamoto and ITIL for Improvement Strategy on Incident Ticket Services", International Journal of Innovative Technology and Exploring Engineering, 2019, 8(10), 897-903

46. Vayvay O., Dogan O, Ozel S., "Forecasting Techniques In Fast Moving Consumer Goods Supply Chain: A Model Proposal", Int. Journal of Information Technology and Business Management, 2013, Vol. 16 No.1, pp. 118-128

47. Sarac A., Absi N., Dauzere, Peres S., "A Literature Review on The Impact of RFID Technologies on Supply Chain Management", Int. Journal of Production Economics, 2010, 128, Issue 1, 77-95 https://doi.org/10.1016/j.ijpe.2010.07.039

48. Rampal S., Balasundaram S., "Application of Extreme Learning Machine Method for Time Series Analysis", Int. Journal of Electrical and Computer Engineering. 2007, 2(8), 549-555

49. Patil, Ami, Deka, Paresh, " An extreme learning machine approach for modeling evapotranspiration using extrinsic inputs", Journal Computers and Electronics in Agriculture. 2016, 121, 385-392

50. Rezaei J., Kothadiya O., Tavasszy L., Kroesen M., "Quality assessment of airline baggage handling systems using Servqual and BWM", Tourism Management. 2018, 66, 85-3

51. Omrani H., Alizadeh A., Amini M., "A new approach based on BWM and Multimoora methods for calculating semi human development index" Sci. 2019

52. Zavadskas E.K., Turskis Z., "A new additive ratio assessment (ARAS) method in multi criteria decision making", Technological and Economic Development of Economy. 2010, 16(2), 159-172. https://doi.org/10.3846/tede.2010.10 